\title{
The European Research on Severe Accidents in Generation-II and -III Nuclear Power Plants
}

\author{
Jean-Pierre Van Dorsselaere, ${ }^{1}$ Ari Auvinen, ${ }^{2}$ David Beraha, ${ }^{3}$ \\ Patrick Chatelard, ${ }^{1}$ Christophe Journeau, ${ }^{4}$ Ivo Kljenak, ${ }^{5}$ Alexei Miassoedov, ${ }^{6}$ \\ Sandro Paci, ${ }^{7}$ Th. Walter Tromm, ${ }^{6}$ and Roland Zeyen ${ }^{8}$ \\ ${ }^{1}$ Institut de Radioprotection et de Sûreté Nucléaire (IRSN), Cadarache, BP3 13115, Saint-Paul-lez-Durance, Cedex, France \\ ${ }^{2}$ VTT Technical Research Centre, Vuorimiehentie 5, Espoo, Finland \\ ${ }^{3}$ Gesellschaft für Anlagen- und Reacktorsicherheit mbH (GRS), Forschungsinstitute, 85748 Garching, Germany \\ ${ }^{4}$ Commissariat à l'Energie Atomique et aux Energies Alternatives (CEA), DEN/STRI/LMA, 13108 Saint-Paul-lez-Durance, \\ Cedex, France \\ ${ }^{5}$ Jozef Stefan Institute (JSI), Jamova cesta 39, Sl-1000, Ljubljana, Slovenia \\ ${ }^{6}$ Karlsruhe Institute of Technology (KIT), Hermann-von-Helmholtz-Platz 1, 76344 Eggenstein-Leopoldshafen, Germany \\ ${ }^{7}$ Dipartimento di Ingegneria Meccanica, Università di Pisa, Via Diotisalvi 2, 56126, Pisa, Italy \\ ${ }^{8}$ European Commission Joint Research Centre, Institute for Energy and Transport (JRC/IET), Westerduinweg 3, P.O. Box 2, \\ 1755 ZG Petten, The Netherlands
}

Correspondence should be addressed to Jean-Pierre Van Dorsselaere, jean-pierre.van-dorsselaere@irsn.fr

Received 23 December 2011; Accepted 10 February 2012

Academic Editor: Gilberto Espinosa-Paredes

Copyright ( $\odot 2012$ Jean-Pierre Van Dorsselaere et al. This is an open access article distributed under the Creative Commons Attribution License, which permits unrestricted use, distribution, and reproduction in any medium, provided the original work is properly cited.

Forty-three organisations from 22 countries network their capacities of research in SARNET (Severe Accident Research NETwork of excellence) to resolve the most important remaining uncertainties and safety issues on severe accidents in existing and future water-cooled nuclear power plants (NPP). After a first project in the 6th Framework Programme (FP6) of the European Commission, the SARNET2 project, coordinated by IRSN, started in April 2009 for 4 years in the FP7 frame. After 2,5 years, some main outcomes of joint research (modelling and experiments) by the network members on the highest priority issues are presented: in-vessel degraded core coolability, molten-corium-concrete-interaction, containment phenomena (water spray, hydrogen combustion...), source term issues (mainly iodine behaviour). The ASTEC integral computer code, jointly developed by IRSN and GRS to predict the NPP SA behaviour, capitalizes in terms of models the knowledge produced in the network: a few validation results are presented. For dissemination of knowledge, an educational 1-week course was organized for young researchers or students in January 2011, and a two-day course is planned mid-2012 for senior staff. Mobility of young researchers or students between the European partners is being promoted. The ERMSAR conference is becoming the major worldwide conference on SA research.

\section{Introduction}

Despite the accident prevention measures adopted in nuclear power plants (NPPs), some accident scenarios, in very low probability circumstances, may result in severe accidents (SA) with core melting and plant damage and to dispersal of radioactive materials into the environment, thus constituting a hazard for the public health and for the environment. This was unfortunately underlined by the accidents in the
Japanese Fukushima-Daiichi NPPs in March 2011. After 4 years in the 6th Framework Programme (FP6) of the European Commission, the SARNET (Severe Accident Research NETwork of Excellence) network (http://www.sar-net.eu), coordinated by the French Institut de Radioprotection et de Sûreté Nucléaire (IRSN), is continuing to operate in FP7 [1] for 4 years since April 2009. The objective is to enhance the coordination of the national efforts in order to optimise the use of the available expertise and the experimental facilities 
for resolving the remaining issues for enhancing the safety of existing and future NPPs.

The work focuses on the highest priority safety issues still to be resolved [2], including the realization of experiments and the assessment of the ASTEC integral computer code [3], jointly developed by IRSN and the German Gesellschaft für Anlagen und Reaktorsicherheit mbH (GRS) to simulate the NPP behaviour during a postulated SA. The present paper shows some R\&D selected results at midterm of the project.

\section{THE Sarent Network}

The network gathers 43 partners from 22 countries in Europe, Canada, Korea, United States, and India (see Table 1).

A Steering Committee of 10 members is in charge of strategy and decisions, advised by an Advisory Committee, composed of external end-user organisations (utilities or safety authorities). A General Assembly, composed of one representative of each SARNET partner, plus the EC representative, is called periodically for information and consultation on the progress of the activities, the work orientations and the Steering Committee decisions. A Management Team, composed of the network coordinator and of the work-package leaders, is entrusted with the day-today management of the network. The Joint Programme of Activities (JPA) is broken down into 8 work-packages pertaining to the three following types of activities:

(i) integrating activities, aiming at strengthening links between the partner organizations,

(ii) spreading of excellence,

(iii) joint research activities.

In the SARNET FP6 project, an approach based on the Phenomena Identification and Ranking Table (PIRT) was carried to rank the priority of R\&D issues. The following issues have been selected as highest priority: in-vessel corium and debris coolability, molten corium concrete interaction (MCCI), fuel-coolant interaction, hydrogen mixing and combustion in containment, impact of oxidising conditions on source term, and iodine chemistry.

A review and update of these priorities will be performed in 2012 by a group of ad-hoc experts. Based on the analysis of R\&D progress since 4 or 5 years and on results from Level 2 Probabilistic Safety Assessment (PSA2) studies, it may reorient priorities and identify potential new experimental and theoretical programmes to address these issues. It should also account for the impact of the Fukushima-Daiichi accidents.

As an important integrating activity, the ASTEC integral computer code, jointly developed by IRSN and GRS to predict NPP behaviour during a postulated SA, plays a key role in the network by capitalizing the SA knowledge through new physical models. Besides, efforts are currently underway for the extension of its applicability to BWR and CANDU NPP types (see Section 7.1).

\section{Corium and Debris Coolability}

The major objective of the work on corium and debris coolability is to reduce or possibly solve the remaining uncertainties on the ability of cooling structures and materials during SA, either in the core or in the vessel lower head or in the reactor cavity, in order to limit the progression of the accident. The work comprises experimental and modelling activities, with strong crosscoordination between tasks. Substantial knowledge now exists concerning cooling of a large intact and rod-like geometry. A large part of the effort is being directed now on cooling of a debris bed, in order to demonstrate effective cooling modes and to establish cooling rates and limits.

The analysis of data on degraded core reflooding indicates that major gaps in knowledge till remain in the areas of debris and molten pool. To address these issues, POMECO (KTH) [4] and DEBRIS (IKE) [5] analytical experiments with debris beds are performed to support the quantification of basic laws and coolability behaviour. Top and bottom flooding (quenching) of hot debris (up to $900^{\circ} \mathrm{C}$ ) can be investigated in the DEBRIS facility, also at elevated pressures. New POMECO test facilities are constructed to perform isothermal and boiling two-phase flow experiments with better instrumentation and flexibility to accommodate various prototypical conditions. POMECO aims at analyses under boil-off conditions with emphasis on basic laws and specific 2D effects (downcomers), more oriented at lower head or exvessel situations but also addressing basically the situation in the degrading core. Both DEBRIS and POMECO deal with irregular particles aiming at representing realistic debris.

IRSN is planning larger size quenching experiments $[6,7]$ with $2 \mathrm{D}$ porous media, which allows a multidimensional progression of the quench front in the PEARL programme. Preliminary reflooding experiments were carried in the PRELUDE facility, involving a debris bed of $4 \mathrm{~mm}$ particles inside a $110 \mathrm{~mm}$ external diameter and $100 \mathrm{~mm}$ height test section, at atmospheric pressure. Parameters investigated were

(i) inlet water velocity between 1 and $8 \mathrm{~mm} / \mathrm{s}$ (4 to $30 \mathrm{~m}^{3} / \mathrm{h} / \mathrm{m}^{2}$ ), in the range foreseen in PEARL test matrix,

(ii) power at $300 \mathrm{~W} / \mathrm{kg}$ (maintained or not during the reflooding phase),

(iii) initial temperature before reflooding at $420 \mathrm{~K}, 500 \mathrm{~K}$, $600 \mathrm{~K}$ and $1000 \mathrm{~K}$.

Additional PRELUDE experiments were performed to evaluate the power distribution inside a larger debris bed diameter (from 110 to $280 \mathrm{~mm}$ ) using stainless amagnetic steel particles, 2 and $4 \mathrm{~mm}$ in diameter, up to $300 \mathrm{~W} / \mathrm{kg}$. This campaign ended with two experiments with a heating sequence of a debris bed (test section diameter $180 \mathrm{~mm}$, particles $4 \mathrm{~mm}$ ) up to $1000 \mathrm{~K}$ at about 140 and $200 \mathrm{~W} / \mathrm{kg}$ before the water injection. Those experiments were well instrumented with lot of thermocouples inside the debris bed (different radial and axial positions) to follow the water front propagation along time (Figure 1, where thermocouples measurements at different axial levels are shown). 
TABLE 1: List of SARENT partners.

\begin{tabular}{|c|c|c|}
\hline Partner & Short name & Country \\
\hline Institut de Radioprotection et de Sûreté Nucléaire & IRSN & France \\
\hline KFKI Atomic Energy Research Institute & AEKI & Hungary \\
\hline AREVA NP GmbH & AREVA GmbH & Germany \\
\hline AREVA NP SAS & AREVA NP SAS & France \\
\hline Budapest University of Technology and Economics & BME & Hungary \\
\hline Commissariat à l'Energie Atomique et aux Energies Allternatives & CEA & France \\
\hline Ricerca Sul Sistema Energetico—RSE SpA & RSE & Italy \\
\hline Chalmers tekniska högskola $\mathrm{AB}$ & CHALMERS & Sweden \\
\hline Centro de Investigaciones Energeticas MedioAmbientales y Tecnologicas & CIEMAT & Spain \\
\hline National Centre for Scientific Research “DEMOKRITOS” & DEMOKRITOS & Greece \\
\hline Electricité de France SA & $\mathrm{EDF}$ & France \\
\hline Energy Institute JSC Sofia & EI & Bulgaria \\
\hline Agenzia Nazionale per le Nuove Tecnologie, l'Energia e lo Sviluppo Economico Sostenibile & ENEA & Italy \\
\hline Forschungszentrum Juelich GmbH & JÜLICH & Germany \\
\hline Karlsruher Institut fuer Technologie & KIT & Germany \\
\hline Gesellschaft für Anlagen—und Reaktorsicherheit mbH & GRS & Germany \\
\hline National Autonomous Company for Nuclear Activities Nuclear Research Subsidiary Pitesti & INR & Romania \\
\hline Institute for Nuclear Research and Nuclear Energy & INRNE & Bulgaria \\
\hline Inzinierska Vypoctova Spolocnost Trnava s.r.o. & IVS & Slovakia \\
\hline Jozef Stefan Institute & JSI & Slovenia \\
\hline Kungl Tekniska Högskolan & KTH & Sweden \\
\hline Lithuanian Energy Institute & LEI & Lithuania \\
\hline National Nuclear Laboratory & NNL & UK \\
\hline Nuclear Research \& Consultancy Group v.o.f. & NRG & Netherlands \\
\hline Paul Scherrer Institut & PSI & Switzerland \\
\hline Ruhr-Universität Bochum & RUB-LEE & Germany \\
\hline Tractebel Engineering SA & TRACTEBEL & Belgium \\
\hline Thermodata & THERMODATA & France \\
\hline Technical University of Sofia & TUS & Bulgaria \\
\hline Urad Jadroveho Dozoru Slovenskej Republiky & UJD SR & Slovakia \\
\hline Ustav Jaderneho Vyzkumu Rez a.s. & UJV & Czech Rep. \\
\hline University of Newcastle upon Tyne & UNEW & UK \\
\hline Dipartimento di Ingegneria Meccanica, Nucleare e della Produzione—Università di Pisa & UNIPI & Italy \\
\hline Universität Stuttgart & IKE & Germany \\
\hline NUBIKI Nuclear Safety Research Institute & NUBIKI & Hungary \\
\hline VTT Technical Research Centre of Finland & VTT & Finland \\
\hline VUJE Trnava, a.s.-Inzinierska, Projektova a Vyskumna Organizacia & VUJE & Slovakia \\
\hline Commission of the European Communities_-Joint Research Centres & JRCs & $\mathrm{EU}$ \\
\hline Atomic Energy Canada Limited & AECL & Canada \\
\hline Korea Atomic Energy Research Institute & KAERI & Korea \\
\hline United States Nuclear Regulatory Commission & USNRC & USA \\
\hline Korea Institute of Nuclear Safety & KINS & Korea \\
\hline Bhabha Atomic Research Centre & BARC & India \\
\hline
\end{tabular}


The measurements of the injected water flow, as well as the steam flow rate generated during reflooding, were accurately obtained by mean of adapted sensors to reach a very good water/steam balance.

The PEARL programme will simulate the reflooding of a debris bed, characteristic of an in-core debris bed, surrounded by a more permeable medium (such as intact structures and rods). PEARL goes beyond DEBRIS and PRELUDE quenching analyses by the larger facility size and thus the possibility to perform extended analyses on multidimensional effects. It will also provide a general basis for the assessment of the overall behaviour described in the codes (both in- and exvessel phenomena).

Modelling of the coolability of porous media has indicated the importance of multidimensional effects. Different quenching analyses by the partners showed agreement concerning a strongly favoured coolability by inflow of water from lateral water-filled regions of the core with higher porosities. Since lateral water inflow, especially via lower regions, strongly improves coolability, in general the coolability is much better than concluded from 1D analyses with top flooding, and 2D/3D computer codes including adequate descriptions of constitutive laws are required to analyse the real coolability situation [8]. The mechanistic codes ATHLET-CD/WABE (GRS, IKE) and ICARE/CATHARE (IRSN) codes are being validated on the above-quenching experiments. This should help to improve their models with the ultimate objective to propose an adequate model for the ASTEC integral code.

Also, it is necessary to improve the modelling of formation of porous media in the core. Alternatively, for assumed configurations, degradation and melting, pool formation and melt release must be analysed to reveal major trends taking into account water supply (cooling versus melt pool formation).

\section{Molten Corium Concrete Interaction}

MCCI can eventually lead to containment basemat meltthrough and thus has been considered as high priority SA research topic. A significant programme of joint activities is organized within SARNET on this issue with the participation of 17 organizations.

4.1. 2D Ablation Profiles. Contrary to what was previously expected, the 2D MCCI experiments performed at Argonne National Laboratory [9] and at CEA Cadarache [10, 11] have shown that, except for limestone-rich concretes, the concrete ablation is anisotropic: lateral ablation is significantly larger than axial ablation. Anisotropic ablation has also been observed in the under-reactor room of the Chernobyl4 reactor [12], where a marked lateral ablation of the (silica-rich) granitic concrete has been observed. So the experimental observations of ablation anisotropy should not be attributed solely to scale or heating technique artefacts and must be understood in order to achieve predictive modelling of concrete ablation during a postulated SA.

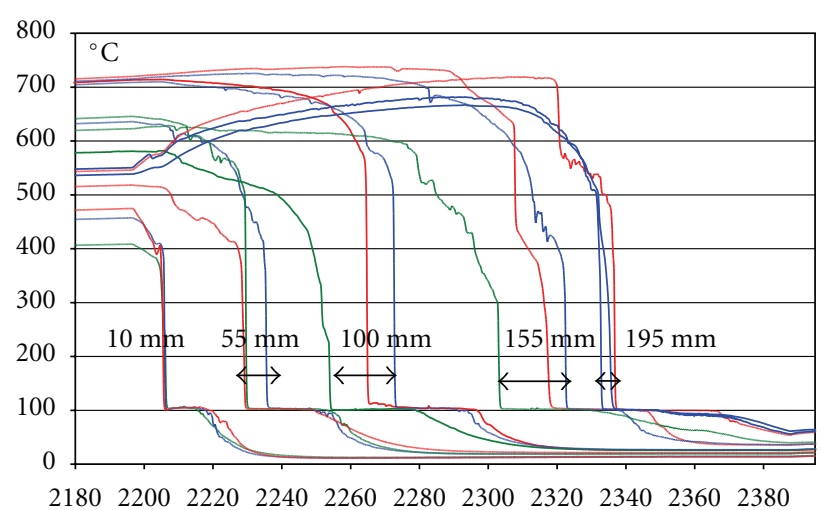

(s)

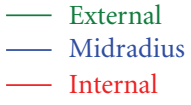

FIgURE 1: PRELUDE measurements of the water front evolution along time.

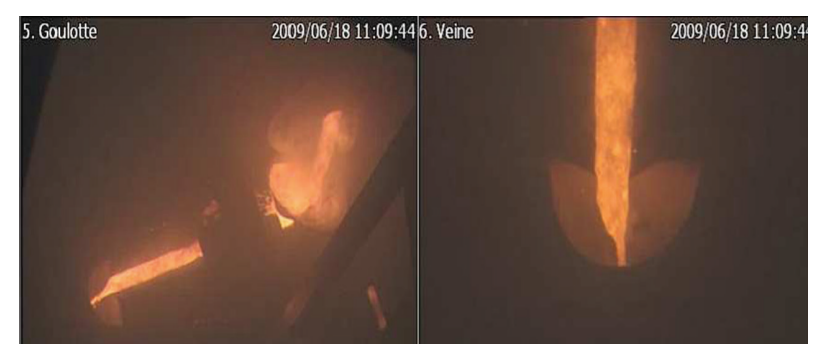

Figure 2: Pictures of VULCANO VB-ES-U2 test during corium pouring phase. Left: Corium pouring from the plasma arc rotating furnace (upper right) to the concrete cavity (lower left). Right: Zoom on the concrete hemicylindrical cavity.

To contribute to the understanding of this phenomenon, CEA has launched, with SARNET and national supports, a series of Separate-Effect-Tests in the VULCANO facility. Two experiments have been performed (Figure 2) with respectively a concrete made of decarbonated limestone (VBES-U2), which presented anisotropic ablation and with a siliceous mortar (i.e., a "concrete" without the aggregates above $2 \mathrm{~mm}$ ) which is still awaiting post test examinations (VB-ES-U3).

The VB-ES-U2 experiment clearly showed that neither the molten concrete physical properties nor the physicochemical properties cause the transition from anisotropy to isotropy, since two concretes having the same melt composition (after decarbonation) present very different ablation patterns. It is also very unlikely that the gas superficial velocity is the cause of isotropy, since these parameters were close in the VULCANO experiments with limestone and clinker concretes while the ablation patterns were different. Three remaining effects need to be considered: effect of large unmelted gravel, effect of concrete shrinkage, effect of the gas superficial momentum (or mass flow rate). The analysis of the latest experiment and of one or two further experiments should allow narrowing the investigations on the origin 
of ablation anisotropy. Temperatures in the pool, in the concrete and on the pool surface are monitored throughout the experiment to be compared with code calculations.

Since MCCI thermalhydraulics is strongly coupled with thermochemistry, some analytical experiments are conducted to determine melt liquidus composition at UJV and ITU. They contribute, with the assessment of all the material analyses, to the validation or improvement of the NUCLEA thermodynamic database [13]. The CLARA facility in CEA provides new thermalhydraulic data on convection with gas sparging in the bottom and on the sides of the pool. These experiments are important to derive empirical models for prediction of MCCI ablation profiles.

In parallel, a benchmark exercise between several computer codes is under way on 2 earlier VULCANO experiments.

4.2. Effect of the Metallic Phase. The effect of the metallic phase must be considered, especially because models indicate that a heavy metallic layer would concentrate the heat fluxes towards the bottom. The MOCKA large scale $(\sim 1$ ton of corium) facility is under construction at KIT to study the effect of the metallic phase with high temperature simulant materials. Experiments with prototypic materials (oxidic corium and steel) were performed in the VULCANO facility [14] at the $50 \mathrm{~kg}$ scale and in the SICOPS facility (in AREVA$\mathrm{NP}$ GmbH) [15] at a smaller scale. Both experiments showed a significant metal oxidation. The next planned experiments will last shorter so that a sufficient volume of metal remains in order to analyze its spatial repartition during Posttest examinations. Interpretation work of all available metaloxide tests using both stimulant and prototypical materials has been performed, which led to review the metal/oxide stratification criterion. Reactor MCCI studies have been performed with the ASTEC code using this more realistic criterion: it led to the melt-trough of a $4 \mathrm{~m}$ thick basemat in more than 5 days and only 1 day for an unrealistic fixed configuration with the metallic phase under the oxide one. Further experimental and theoretical investigations are necessary, especially for cases with siliceous concrete that will promote stratification due to the low gas production of its ablation. They will be devoted to the metal oxidation kinetics but also to determine the effects of a stratified configuration. For this last issue, information will be obtained in particular from Direct Numerical Simulation of heat transfer due to sparging of gas bubbles through the interface between a heavy metallic layer and a lighter heated oxide layer [16]. Figure 3 shows the temperature field in an IRSN calculation.

4.3. Late Water Cooling of MCCI. Research activities are underway to assess the capability of water cooling starting after the pouring of corium in the cavity. Although CCI6 results [17] suggest that early water flooding (i.e., at a time when the concrete molten fraction is low) has a good coolability potential that must be confirmed by further experiments, the efficiency of late top flooding seems more doubtful, especially for siliceous concretes. Bottom flooding, for example, using the COMET concept [18], is being studied
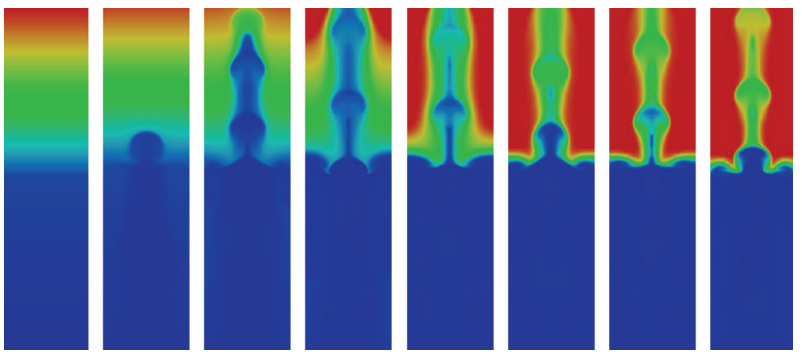

FIgURE 3: Direct Numerical Simulation of heat transfer induced by a bubble swarm at the metal-oxide interface.

as an efficient alternative to top flooding. IKE is conducting modelling and interpretation of the VULCANO COMET experiment and reactor scale calculations. The porosity formation in the melt layer and the cooling process due to the injection of water via porous concrete at bottom is calculated with the MEWA code. Figure 4 shows the status of quenching after about $300 \mathrm{~s}$ (melt temperature field) together with water and steam velocities.

4.4. Bringing Research to Reactor Applications. The research activities conducted with SARNET are always linked to reactor applications. For MCCI, these applications are organized around benchmarks between different computer codes. A benchmark of a generic VVER-1000 MCCI is under way. Lessons from the MCCI which took place during Chernobyl accident are also being considered.

\section{Containment Issues}

The considered safety issue is the threat to the containment integrity due to two types of highly energetic phenomena: steam explosion and hydrogen combustion. Several benchmarks were launched involving simulation codes (LumpedParameter (LP) or Computational Fluid Dynamics (CFD)) on different physical phenomena or safety systems, such as containment sprays, hydrogen combustion, steam condensation, interaction between Passive Autocatalytic Recombiners and containment atmosphere, plus a theoretical benchmark on a generic NPP containment including the most important components. Some benchmarks already achieved significant results.

5.1. Benchmark on Containment Sprays. The first part of the spray benchmark [19] consisted in simulating an elementary heat and mass transfer experiment, done in IRSN: separate uniform droplets were generated and observed in a vessel with a controlled atmosphere. For this exercise, both LP and CFD codes were used. Apart from the organizer IRSN, the following organizations participated in the benchmark: EDF, RSE, GRS, KIT, LEI, NRG, UJV, UJD SR, and UNIPI. Five droplet evaporation and four droplet condensation experiments were simulated. The comparison of code results with the vertical evolutions of the droplet temperature, droplet diameter and vertical velocity, enabled the assessment of droplet models in different codes, as the results were not 


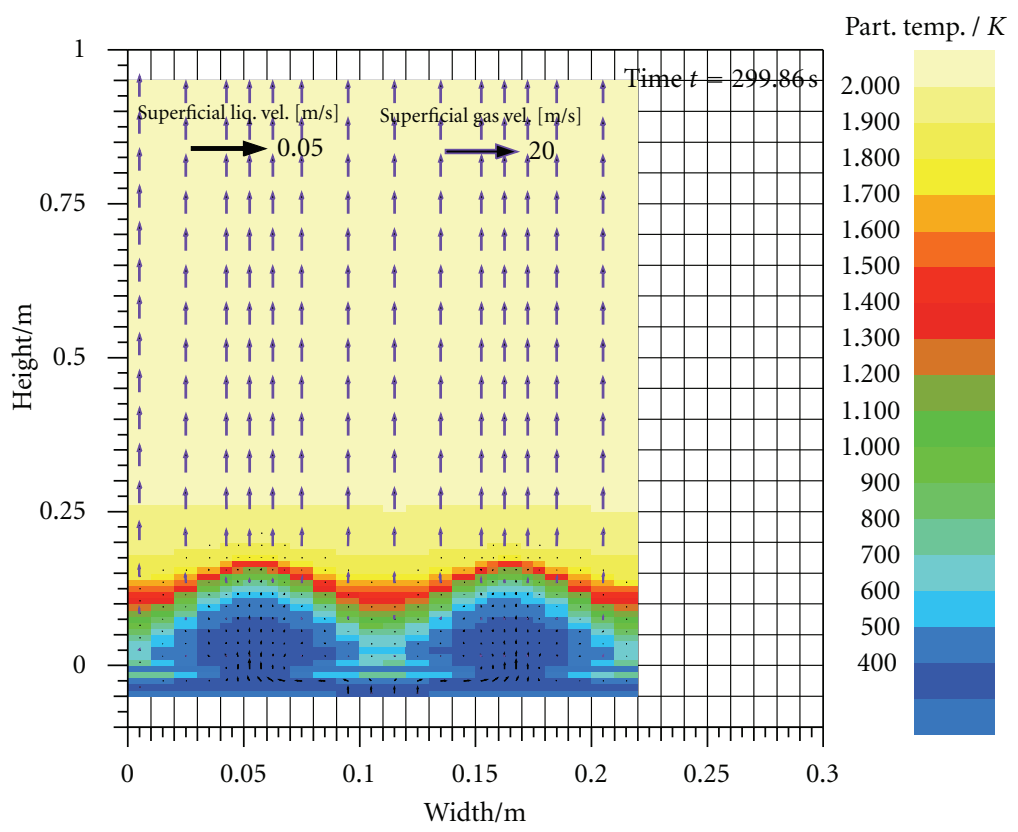

FIgURE 4: MEWA calculation of the velocities and temperatures in the VULCANO COMET experiment.

distorted by the influence of other simulated phenomena. In particular, it appeared that the calculated evaporation rate is mostly too high at ambient conditions.

5.2. Benchmark on Hydrogen Combustion. The benchmark on flame acceleration during hydrogen combustion [20] consists in simulating experiments performed in the ENACCEF $0,8 \mathrm{~m}^{3}$ facility (Figure 5), located at the Centre National de la Recherche Scientifique (CNRS) in Orléans (France). The following organizations have participated in the benchmark: IRSN (organizer and joint owner of the facility), AREVA NP GmbH, GRS, KAERI, LEI, NUBIKI and RUB. Three experiments were simulated, one without obstacles in the acceleration tube and two with obstacles, with different blockage ratios. In all cases, the flame propagation was much better simulated in the later parts of the tube (in the region with obstacles and further) than in the initial part (between the ignition point and the first obstacle). The pressure increase was also mostly well calculated.

5.3. Benchmark on Steam Condensation. Although research of condensation as such does not fall in the field of severe accidents, the modelling of condensation may significantly affect the results of CFD simulations of containment atmosphere mixing and stratification. The purpose of the benchmark [21], which consists in simulating experiments that were performed in the CONAN facility (at UNIPI) with CFD codes, is to compare different existing models with the purpose to identify the most adequate ones. The following organizations have participated: UNIPI (organizer), CEA, FZ Jülich, JSI, KIT, NUBIKI, UJV and AECL. So far, experiments involving condensation during downward forced flow of a steam-air mixture near a condensing vertical plate were

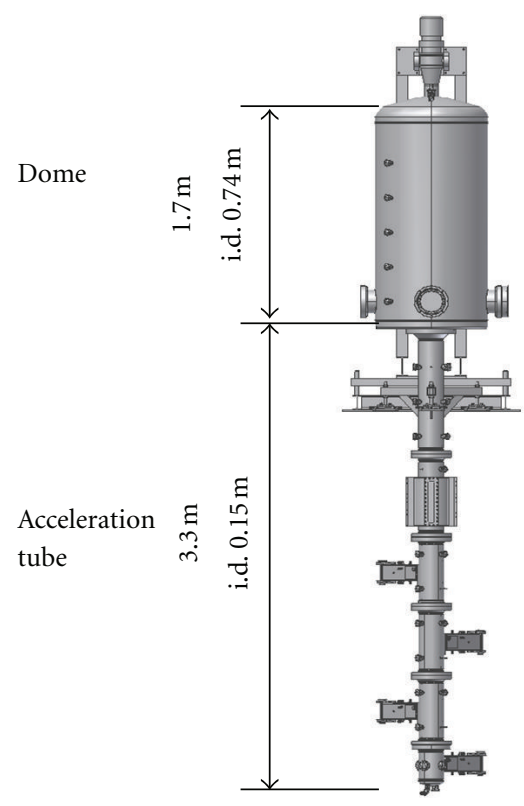

FIGURE 5: ENACCEF experimental facility for performing experiments on hydrogen combustion.

simulated. In general, a good agreement of measured and calculated condensation rates, heat fluxes and plate temperatures was obtained by most participants. In the next phase of the benchmark, experiments and simulations are planned to involve natural convection, which will be closer to the expected physical conditions during a severe accident.

5.4. Benchmark on Generic Containment. When comparing simulation results of severe accidents in actual NPPs, 


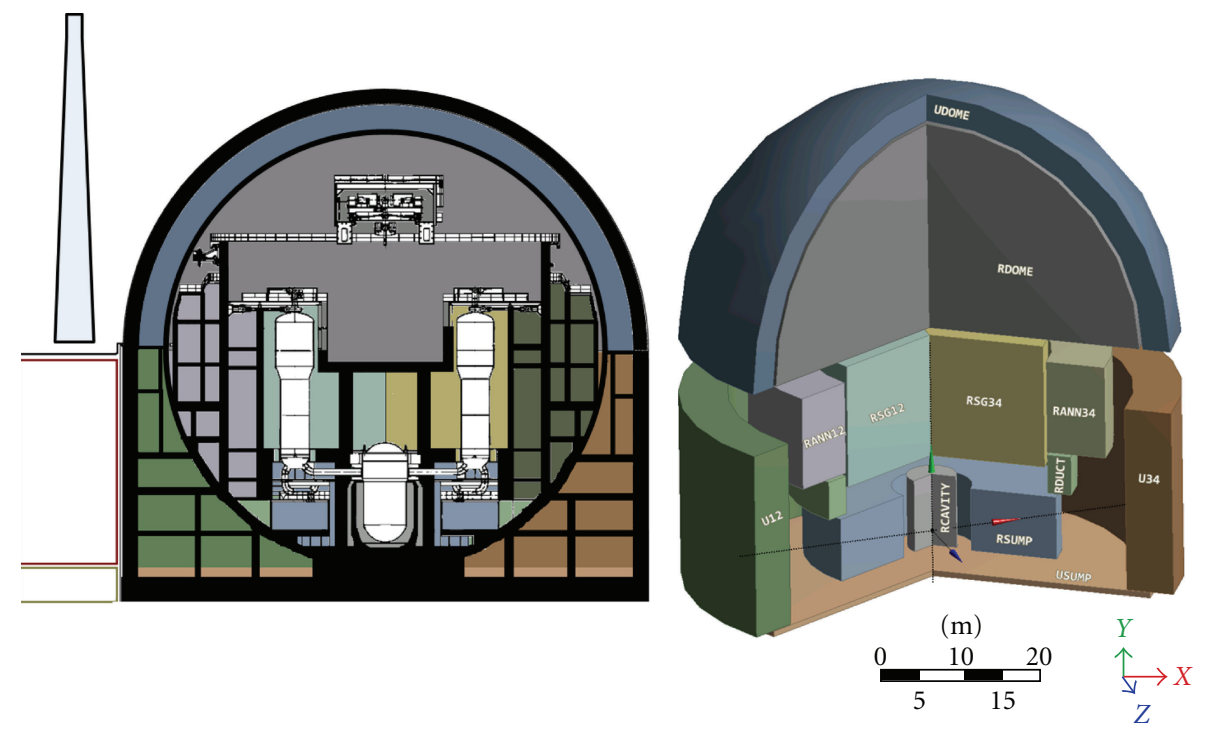

FIgURE 6: Schematic view of the "generic" NPP containment.

obtained by different LP codes, the differences are often distorted by different assumptions and modelling, adopted by different users. The basic idea of the benchmark on "generic" containment is to compare code results by simulating a transient in a precise and unique containment model, based on the containment of a German NPP [22] (Figure 6). Apart from the organizer FZ Jülich, the following organizations have participated in the first phase: AREVA GmbH, ENEA, RSE, JSI, GRS, IRSN, NRG, NUBIKI, RUB, TUS, UJV, UNIPI and VTT. Although most calculated results were similar, an interesting outcome of the 1st phase of the benchmark is that significant differences may still be observed, due mainly to:

(i) differences in applied thermal-hydraulic models,

(ii) prediction of different flow patterns by different codes.

\section{Source Term Issues}

In the source term area, collaboration has been especially active concerning iodine behaviour in the containment. Experimental and analytical studies focused on volatile iodine formation from iodine-loaded paints and possible destruction of gaseous iodine species by their reactions with air radiolysis products. Some examples of the extensive work performed are summarized here.

The EPICUR S2-6 analytical test series was launched by IRSN to validate and develop models for gaseous organic iodide formation from a painted surface loaded with iodine [20]. Iodine is assumed to be adsorbed onto a painted coupon, and then to react with the organics in the paints. In these experiments, the influence of the temperature, humidity, and iodine surfacic concentration was studied. One objective was also to study the effect of residence time in the irradiation vessel on the nature and proportions of volatile species formed and the duration of the irradiation in order to quantify the release kinetics from the coupon after $8 \mathrm{~h}$ of irradiation. Before the experiments the coupons were loaded with labelled molecular iodine $\left({ }^{131} \mathrm{I}\right)$ by Dushman's reaction. Then the coupons were irradiated in a vessel and the volatilised iodine species were swept to a May-Pack. The May-Pack is composed of selective filters which allow speciation between molecular and organic iodide. The iodine compounds trapped in the different filters are $\gamma$-counted online with NaI-probes set above each filter group.

The S2-6 series revealed two important and partly surprising facts. The fraction of iodine volatilised as organic iodide decreased when iodine loading on painted coupons increased. A 30-hour experiment also revealed that there was still release of iodine after 8 hours of irradiation, but the volatilisation was slower. IRSN and NNL have proposed a joint preliminary interpretation of the S2-6 test series based on mechanistic considerations. Mechanisms of interaction between iodine and main functions of polymeric paint molecules have been identified and ranked according to their influence in organic iodine production. Then an explanation of the influence of the most influent parameters, that is, the iodine loading, temperature and relative humidity, has been proposed in the light of those mechanisms. The development of a new ASTEC model of iodine interaction with paint is under way by determining the kinetic constants of those mechanisms.

Experimental studies on radiolytic oxidation of elemental iodine and methyl iodide were carried out in the EXSI facility by VTT and Chalmers University [23]. The aim was to verify the possible formation of iodine-containing aerosol species, when gaseous iodine is exposed to air radiolysis products. The reactions take place in a flow furnace with temperature varying from $50^{\circ} \mathrm{C}$ to $120^{\circ} \mathrm{C}$ and residence time from 2 to 7 seconds. Up to four ultra-violet C (UVC) lamps were used as a source of ionizing radiation and to produce ozone in various oxygen concentrations. Ozone was also 
produced with an ozone generator. The effect of humidity on oxidation of iodine was also studied.

The aerosol particles formed were collected on plane filters, after which gaseous iodine was trapped in a $\mathrm{NaOH}-$ water solution. The amount of iodine in both filters and trapping bottles was analysed using an Inductively Coupled Plasma-Mass Spectrometer (ICP-MS). Particle mass flow rates, number concentrations and size distributions were measured on-line using aerosol instrumentation. Speciation of gaseous reaction products was measured also on-line with Fourier Transform Infrared Spectroscopy (FTIR). The morphology as well as the elemental composition of the particles was determined with Scanning Electron Microscope Energy Dispersive X-Ray Analysis (SEM-EDX).

It was found that the formation of aerosol particles was very rapid when ozone was present with either elemental iodine or methyl iodide. A similar increase in aerosol mass concentration was found with increasing UV radiation intensity. Regardless of the ozone generation technique, increasing reaction temperature also increased aerosol mass concentration. Particle mass concentrations measured in $\mathrm{CH}_{3} \mathrm{I}$ experiments are presented in Figure 7 as a function of radiation intensity and temperature.

The diameter of the primary particles varied between 5$10 \mathrm{~nm}$. Due to the very high number concentration, particles grew by agglomeration. Agglomerate size distribution was log-normal with number median diameter (NMD) varying between $60-120 \mathrm{~nm}$. The size of the agglomerates increased and the number concentration decreased with increasing residence time. The agglomerate size also increased with iodine concentration. SEM-EDX analysis showed that particles contained iodine and oxygen. According to a literature study, the most likely iodine oxide species would be $\mathrm{I}_{2} \mathrm{O}_{4}$, $\mathrm{I}_{2} \mathrm{O}_{5}$ and $\mathrm{I}_{4} \mathrm{O}_{9}$. Depending on experimental conditions, both liquid and solid particles were observed. Iodine oxides in contact with water form hydrated species and the final product is likely to be iodic acid $[24,25]$.

The transport of elemental iodine through the facility was very low when ozone was present, whereas a part of methyl iodide was always detected at the outlet of the system. The presence of ozone promoted retention of iodine in the facility probably by surface reaction. Some deposited iodine evaporated later during the experiments and formed particles in the gas stream. The main gaseous reaction products of organic iodides were methanol and formaldehyde. Especially at elevated temperature other reaction products, such as formic acid and methyl formate, became important as well. The decomposition of $\mathrm{CH}_{3} \mathrm{I}$ and subsequent formation of reaction products was much faster than what is considered in previous studies.

NNL analysed the EXSI methyl iodide experiments with the mechanistic IODAIR code. Methyl iodide decomposition in UV tests was probably due to direct photolysis and reactions with $\mathrm{O}$ atoms. Direct photolysis would favour production of gaseous iodine, whereas reaction with $\mathrm{O}$ atoms would lead to formation of iodine oxide particles. According to modelling, ozone formation was expected to be insignificant, which was confirmed by measurements. Methyl iodide decomposition in experiments with ozone feed was

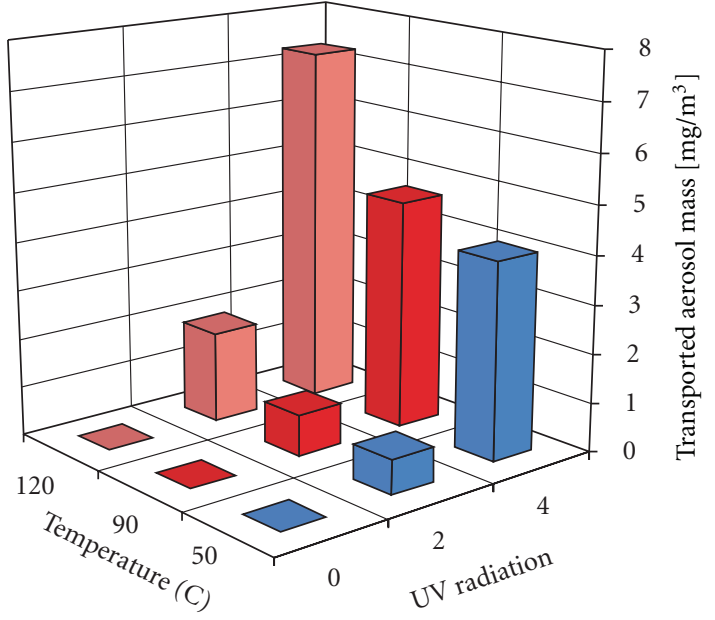

Figure 7: Particle mass concentration in $\mathrm{CH}_{3} \mathrm{I}$ experiments as a function of radiation intensity and temperature.

much higher than predicted by the model. Such result cannot be accounted for only by thermal decomposition of ozone. The test results indicate a direct reaction between methyl iodide and ozone.

To apply the results obtained with UV radiation in reactor safety, further EXSI experiments on methyl iodide oxidation are being carried out using a $20 \mathrm{kGy} / \mathrm{h}{ }^{60} \mathrm{Co}$ source in Chalmers Technical University.

\section{Integrating Activities}

7.1. ASTEC Code Assessment and Improvements. IRSN and GRS jointly develop the ASTEC code to describe the complete evolution of a SA in a nuclear water-cooled reactor [3]. The new series of versions V2 can simulate the EPR (European Pressurised Reactor), especially its external corecatcher, and it includes the advanced core degradation models of the ICARE2 IRSN mechanistic code. Twenty-eight organizations contribute to the assessment of the successive ASTEC versions in the SARNET frame, through validation on reference experiments and through reactor applications for the most important SA scenarios in PWR, VVER and CANDU.

A first revision of the V2.0 version, released in June 2010, included mainly model improvements in the modules ICARE (about corium behaviour in the lower head), MEDICIS (about MCCI in EPR), and CESAR (about thermalhydraulics in the primary and secondary circuits). CESAR uses 0-D components to represent the pressuriser, the vessel upper head or the steam generator (SG) cavity (separator): these volumes may contain a water level, with gas above the water level close to the saturation temperature. Two distinct zones, a lower water/steam zone and an upper gas region, have been modelled in these volumes: in both zones, different pressures (for a correct account for the hydrostatic pressure), wall temperatures (for a correct distribution of heat from walls) and gas temperatures (for a right interface/steam transfer) are now considered. A second revision of the V2.0 


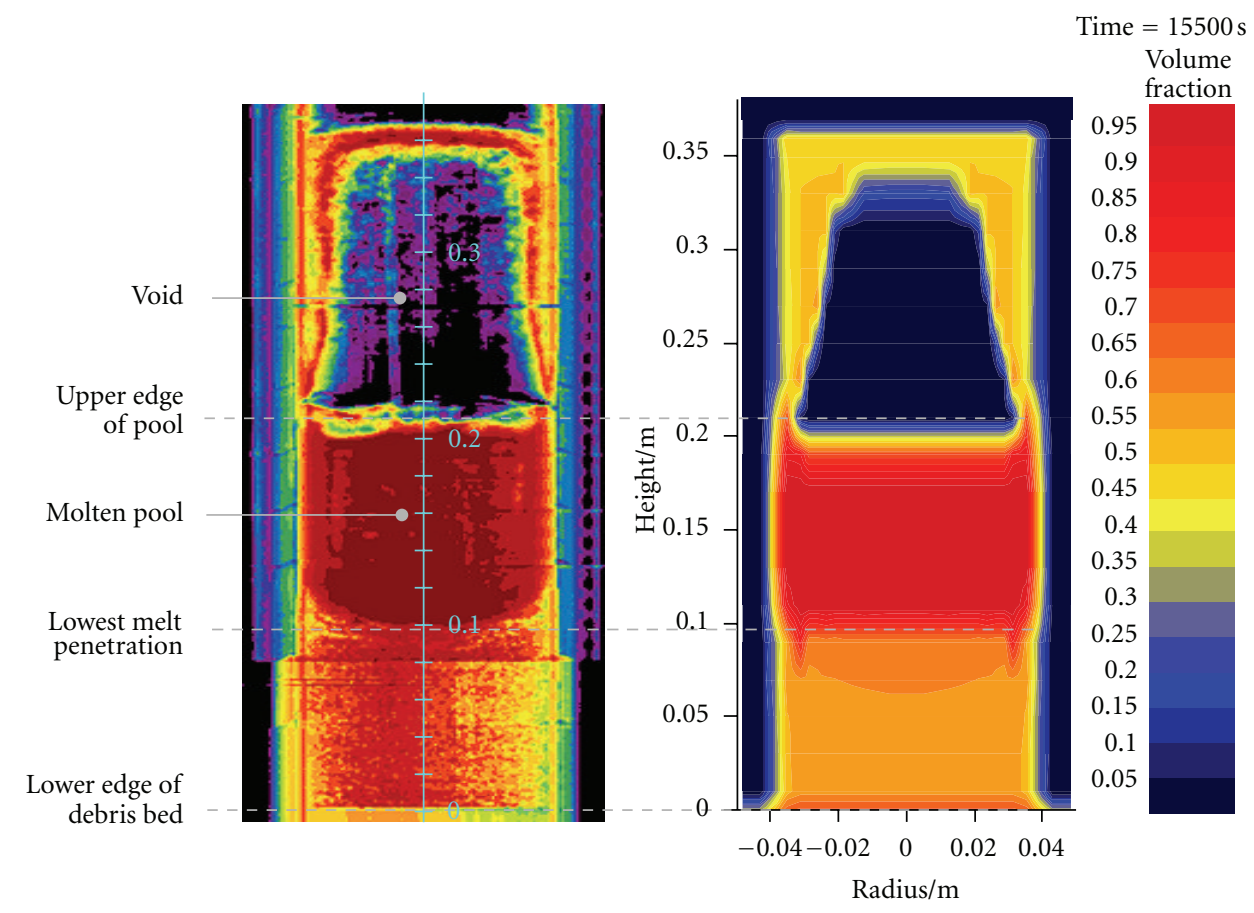

FIGURE 8: Comparison of Phébus FPT4 post-test radiography (left) with calculated volume fraction of material (right).

version was released in December 2011, accounting for the feedback of the maintenance efforts.

As one example of V2 validation, IKE (Germany) applied ICARE2 to the Phébus FPT4 experiment on melting of a debris bed, made of $\mathrm{UO}_{2}$ and $\mathrm{ZrO}_{2}$ particles of 2 to $5 \mathrm{~mm}$ size. The calculated temperatures are in very good agreement with the measurements, which indicates that the heat transport phenomena in the dry debris bed are well described by the chosen Imura/Yagi correlation for the effective heat conductivity and the Gunn correlation for the convective heat transfer. The final material distribution is also very well captured (Figure 8), indicating a very good behaviour of the $2 \mathrm{D}$ magma model. As concerns fission products, the ASTEC V2 prediction is very good for the release of volatile species while a tendency to over-predict the release of medium volatile species is observed.

As another example of V2 assessment, AREVA NP SAS (France) performed a benchmark between the ASTEC V2.0 and MAAP4.07 codes on a transient of failure of SG feed-water system in a PWR 900 MWe. It is additionally supposed here that the active emergency core cooling systems are unavailable: only passive cooling systems (hydroaccumulators) are available. Two ASTEC calculations were performed: the one named CAND using the candling 1D model of corium relocation along the rods and the one named MAGMA using the 2D corium relocation model within the core. The timing of calculated events is similar between both codes during the core degradation phase except for the vessel lower head rupture that occurs sooner with ASTEC. The corium masses in the vessel lower head are close at time of vessel rupture. Figure 9 shows the comparison of the in-vessel hydrogen cumulated release mass: though the

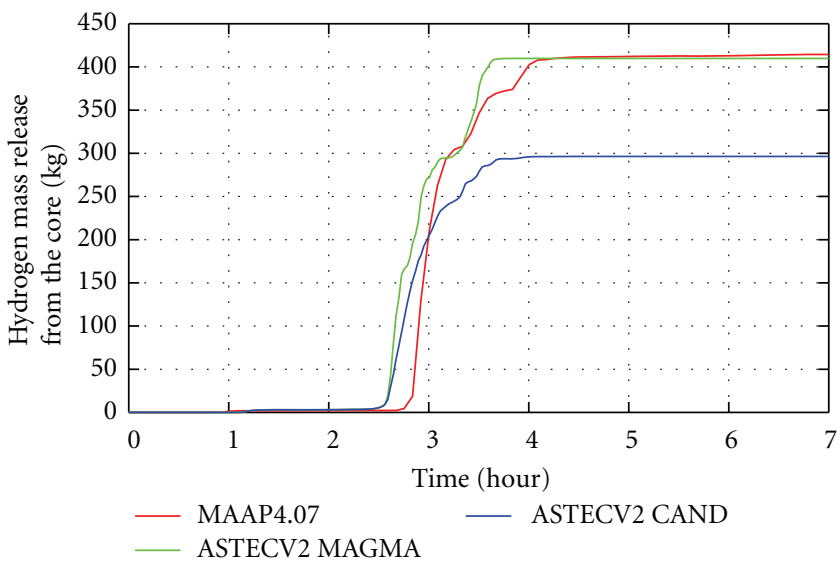

FIGURE 9: Comparison ASTEC-MAAP of produced in-vessel hydrogen in a reactor benchmark.

core degradation phase starts a little bit earlier with ASTEC than with MAAP, a very good agreement is obtained between both codes when using the MAGMA model in ASTEC V2. This comparison will focus in the next months on the exvessel phase and on the behaviour of fission products.

The work done in the SARNET FP6 and FP7 projects has shown that ASTEC models were applicable to BWR and CANDU reactors except for the core degradation phenomena, mainly due to the specific core geometry with metallic boxes around the fuel bundles, like square canisters in BWR and pressure tubes in CANDU. IRSN is currently restructuring the ICARE module to account for these new 
components and for the associated multi-channels thermalhydraulics with coolant flows inside these boxes and between them. Partners also specify new BWR models for the impact of control rod guide tubes and instrument tube structures on corium behaviour in the vessel lower head, as well as for the formation of debris due to corium ejection in a cavity filled with water. New models of CANDU pressure tube thermal creep deformation have also been implemented in the ASTEC development version.

7.2. Storage in DATANET of Experimental Data. The objective of the DATANET database [26] is to collect the available experimental data in a common format in order to ensure preservation, exchange and processing of SA experimental data, including all related documentation on an internet based protected site. The data are both previous experimental data that SARNET partners are willing to share within the network and all new data produced within SARNET. DATANET is based on the STRESA tool developed by the Joint Research Centre (JRC) in Ispra (Italy) and now managed by JRC IET (Institute for Energy) in Petten (The Netherlands). It consists of a network with several local databases where all access rights are managed in accordance with the rules adopted in the SARNET consortium. The protection of confidential data is an important feature that is taken into account as the information security of the database.

In SARNET FP7, three new STRESA nodes were opened and the results of about 270 experiments from more than 20 facilities have now been implemented. The storage by partners of new experiments will continue. JRC IET will also create new local STRESA nodes for partners with a small volume of experimental data and support the users through training sessions when necessary.

\section{Spreading of Excellence}

The existing public website (http://www.sar-net.eu) is being continuously improved to make it more attractive and to provide more information on the SA research field to the general public. For communication between all network members, the e-collaborative Internet Advanced Communication Tool (ACT) is used like in SARNET FP6 project but with substantially improved features.

About 320 papers related to SARNET work in the last 5 years have been presented in conferences or published in scientific journals. Efforts will continue in that direction. The dissemination of information is also done through periodic newsletters or participation to public events.

Three conferences ERMSAR (European Review Meetings on Severe Accident Research) have been organized during the last 5 years successively in France, Germany and Bulgaria as a forum for the SA community. They are becoming one of the major yearly events in the world on this topic. The 4th one was hosted by ENEA (Italy) on May 11-12, 2010 in Bologna (Italy). The next one will be hosted by GRS in Cologne (Germany) on 21-23 March 2012.

The Education and Training programme is focusing on raising the competence level of the university students
(Master and $\mathrm{PhD}$ ) and researchers engaged in SA research. Towards this purpose, in the wake of SARNET FP6 project, education courses are being developed on the SA phenomenology. The teaching will not be a survey but an indepth treatment so that the students and researchers will be able to understand the methodology in the topics further and use analysis computer codes, mainly ASTEC, more effectively for any type of European NPP. The best-estimate analysis will be supplemented with an uncertainty analysis. Links with the European ENEN association (European Nuclear Education Network) will be maintained and strengthened. Besides, training courses will be proposed for plant operators and for researchers who are interested in the severe accident management procedures. Here, the emphasis should be in identifying what these procedures are based on and why they are effective. Three one-week educational courses were organised during the last 5 years, gathering from 40 to 100 persons. A 4th course was organised by University of Pisa and CEA in Pisa in January 2011. The next one, organized by KIT and AREVA GmbH, will take place in Karlsruhe (Germany) mid-2012 for staff in regulatory authorities, utilities or NPPs.

The textbook on SA phenomenology was drafted during the SARNET FP6 project. It covers historical aspects of watercooled reactors safety principles and phenomena concerning in-vessel accident progression, early and late containment failure, fission product release and transport. It contains also a description of analysis tools or codes, of management and termination of SA, as well as environmental management. It gives elements on Generation III reactors. After the final review done in 2011, the publication is planned in early 2012.

A programme enables university students and researchers to go into different laboratories for education and training in the SA area. Some stages for master thesis may be organised in the ENEN framework to obtain the 20 credits (ECTS) necessary for the achievement of the European EMSNE (European Master of Science in Nuclear Engineering) certification. The staff deputation programme is continuing: a researcher from one laboratory can spend several months in another European Laboratory where he/she would participate in an area of the SA research ongoing there.

\section{Conclusion}

After a first phase of four and a half years, the SARNET network of excellence is continuing from April 2009 for four years more. A significant progress is foreseen in the last 18 months of the project towards solving the pending issues for current NPP SA through new experiments and modelling, in particular in the ASTEC integral code used as European reference code. An important task in 2012 will be the update of the SA R\&D priorities, notably using the results of all international programmes (OECD/NEA, ISTP, ISTC...etc) and accounting for the impact of the FukushimaDaiichi accidents. Efforts will continue on the transfer of knowledge to younger generations through the ERMSAR periodic international conferences, educational courses and delegations in laboratories. 
A first step towards a sustainable integration of the European SA research capacities has been reached. A strong link must be kept with the "PSA2 community," in continuation of the ASAMPSA2 EC FP7 project on PSA2 best-practice guidelines [27].

The European SNETP (Sustainable Nuclear Energy Technology Platform), that gathers all nuclear fission actors and aims at providing the stakeholders and the public with a 2020-2050 vision on R\&D, has delegated to SARNET the R\&D SA coordination for Gen.II-III NPPs. The challenge is to prepare the network self-sustainability after the end of EC funding after 2013: such a living and unique pool of experts should assess the remaining issues on SA and propose relevant $\mathrm{R} \& \mathrm{D}$ programmes to address them.

\section{Acknowledgment}

The authors thank the European Commission for funding the SARNET network in FP7 (project SARNET2 N'231747 in the area "Nuclear Fission and Radiation Protection").

\section{References}

[1] J. P. Van Dorsselaere, A. Auvinen, D. Beraha et al., "Status of the SARNET network on severe accidents," in Proceedings of the International Congress on Advances in Nuclear Power Plants (ICAPP '10), pp. 1029-1043, June 2010.

[2] B. Schwinges, C. Journeau, T. Haste, L. Meyer, W. Tromm, and K. Trambauer, "Ranking of severe accident research priorities," Progress in Nuclear Energy, vol. 52, no. 1, pp. 11-18, 2010.

[3] J. P. Van Dorsselaere, C. Seropian, P. Chatelard et al., "The ASTEC integral code for severe accident simulation," Nuclear Technology, vol. 165, no. 3, pp. 293-307, 2009.

[4] L. Li, S. Thakre, and W. Ma, "An experimental study on two-phase flow and coolability of particulate beds packed with multi-size particles," in Proceedings of the 14th International Topical Meeting on Nuclear Reactor Thermal Hydraulics (NURETH '11), Toronto, Ontario, Canada, 2011.

[5] M. Rashid, S. Rahman, R. Kulenovic, M. Bürger, and E. Laurien, "Quenching experiments: coolability of debris bed," in Proceedings of the 14th International Topical Meeting on Nuclear Reactor Thermal Hydraulics (NURETH '11), Toronto, Ontario, Canada, 2011.

[6] N. Stenne, F. Fichot, and J. P. van Dorsselaere, "R\&D on reflooding of degraded cores in SARNET-focus on PEARL new IRSN facility," in Proceedings of the EUROSAFE Forum, Brussels, Belgium, 2009.

[7] G. Repetto, T. Garcin, S. Eymery, P. March, and F. Fichot, "Experimental program on debris reflooding (PEARL) results on PRELUDE facility," in Proceedings of the 14th International Topical Meeting on Nuclear Reactor Thermal Hydraulics (NURETH '11), Toronto, Ontario, Canada, 2011.

[8] F. Fichot et al., "Understanding the effects of reflooding in a reactor core beyond LOCA conditions," in Proceedings of the 4th ERMSAR Conference, Bologna, Italy, 2010.

[9] M. T. Farmer, R. W. Aeschlimann, D. J. Kilsdonk, and S. Lompersky, "A summary of findings from the 2D CoreConcrete Interaction (CCI) test series," in Proceedings of the OECD MCCI-2 Project Seminar, Cadarache, France, 2010.
[10] C. Journeau, P. Piluso, J. F. Haquet et al., "Two-dimensional interaction of oxidic corium with concretes: the VULCANO VB test series," Annals of Nuclear Energy, vol. 36, no. 10, pp. 1597-1613, 2009.

[11] C. Journeau et al., "Two EU-funded tests in VULCANO to assess the effects of concrete nature on its ablation by molten corium," in Proceedings of the 4th ERMSAR Conference, Bologna, Italy, 2010.

[12] S. A. Bogatov et al., "Database on the location and status of nuclear fuel at Unit4 of Chernobyl NPP before and after the accident," Preprint, RRC Kurchatov Institute.

[13] S. Bakardjieva, M. Barrachin, S. Bechta et al., "Improvement of the European thermodynamic database NUCLEA," Progress in Nuclear Energy, vol. 52, no. 1, pp. 84-96, 2010.

[14] C. Journeau, P. Piluso, J. F. Haquet et al., "Oxide-metal corium concrete interaction tests in the VULCANO facility," in Proceedings of the OECD MCCI-2 Project Seminar, Cadarache, France, 2010.

[15] G. Langrock and S. Hellmann, "An overview of AREVA's MCCI laboratory-scale tests with prototypic corium (1D/2D, including mixed metallic/oxidic melts)," in Proceedings of the OECD MCCI-2 Project Seminar, Cadarache, France, 2010.

[16] B. Michel, F. Duval, C. Lapuerta, M. Quintard, and M. Cranga, "Oxide/metal convective heat transfer during MCCI: state of the art and multi-scale modelling using detailed simulation," in Proceedings of the OECD MCCI-2 Project Seminar, Cadarache, France, 2010.

[17] M. T. Farmer, R. W. Aeschlimann, D. J. Kilsdonk, and S. Lompersky, "The CCI-6 large scale core-concrete interaction experiment examining debris coolability under early cavity flooding conditions," in Proceedings of the OECD MCCI-2 Project Seminar, Cadarache, France, 2010.

[18] J. J. Foit, M. Bürger, C. Journeau, H. Alsmeyer, and W. Tromm, "Quenching of melt layers by bottom injection of water in the COMET core-catcher concept," in Proceedings of the 3rd ERMSAR Conference, Nesseber, Bulgaria, 2010.

[19] J. Malet, T. Gelain, S. Mimouni et al., "Single droplet heat and mass transfer modelling for nuclear containment spray applications-SARNET2 benchmark," in Proceedings of the 5th ERMSAR Conference, Cologne, Germany, 2012.

[20] J. Colombani, S. Fillet, C. Pascal, L. Martinet, C. Gomez, and L. Bosland, "Experimental study of organic iodide formation in the containment during a severe accident," in Proceedings of the ICAPP, Nice, France, 2011.

[21] W. Ambrosini, M. Bucci, N. Forgione, F. Oriolo, and S. Paci, "Quick look report on SARNET2 condensation benchmark-2 results," Report DIMNP RL 1252, University of Pisa, 2010.

[22] S. Kelm, P. Broxtermann, S. Krajewski, and H.-J. Allelein, "Report on the generic containment code-to-code comparison—run0," Forschungszentrum Jülich, 2010.

[23] T. Kärkelä, J. Holm, A. Auvinen et al., "Gas phase reactions of organic iodine in containment conditions," in Proceedings of the International Congress on Advances in Nuclear Power Plants (ICAPP '10), pp. 1084-1091, June 2010.

[24] G. Daehlie and A. Kjekshus, "Iodine oxides, I. I2O3.SO3, I2O3.4SO3.H2O, I2O3.SeO3, and I2O4," Acta Chemica Scandinavica, vol. 18, no. 1, pp. 144-156, 1964.

[25] M. W. Chase, "NIST-JANAF thermochemical tables for the iodine oxides," Journal of Physical and Chemical Reference Data, vol. 25, no. 5, pp. 1229-1339, 1996. 
[26] R. Zeyen, "European approach for a perennial storage of severe accident research experimental data, as resulting from EU projects like SARNET, Phébus FP and ISTP," in Proceedings of the ANS Winter Meeting, Washington, DC, USA, 2009.

[27] FP7 project ASAMPSA2, "Advanced safety Assessment Methodologies: level 2 Probabilistic Safety Assessment," 2007, http://www.asampsa2.eu/. 

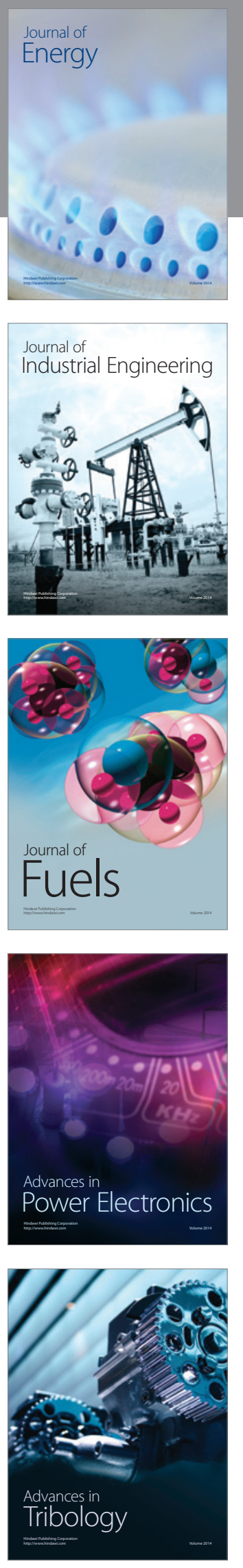
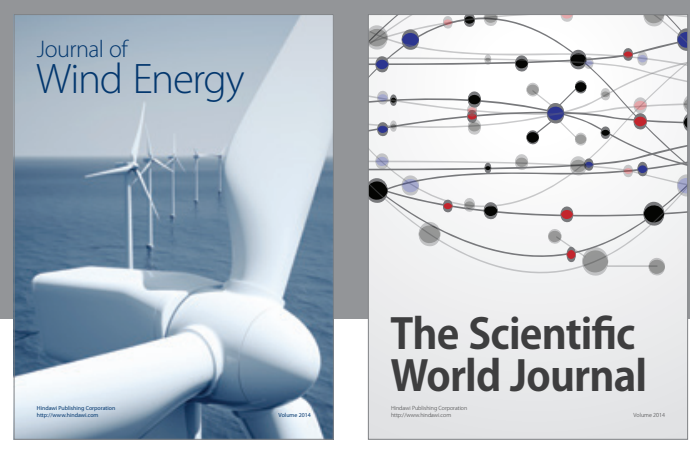

The Scientific World Journal

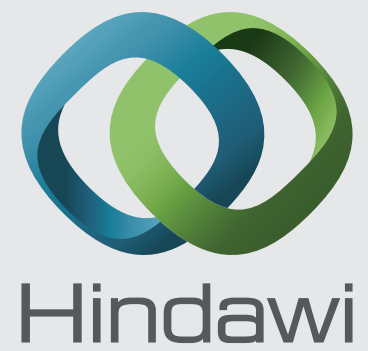

Submit your manuscripts at http://www.hindawi.com
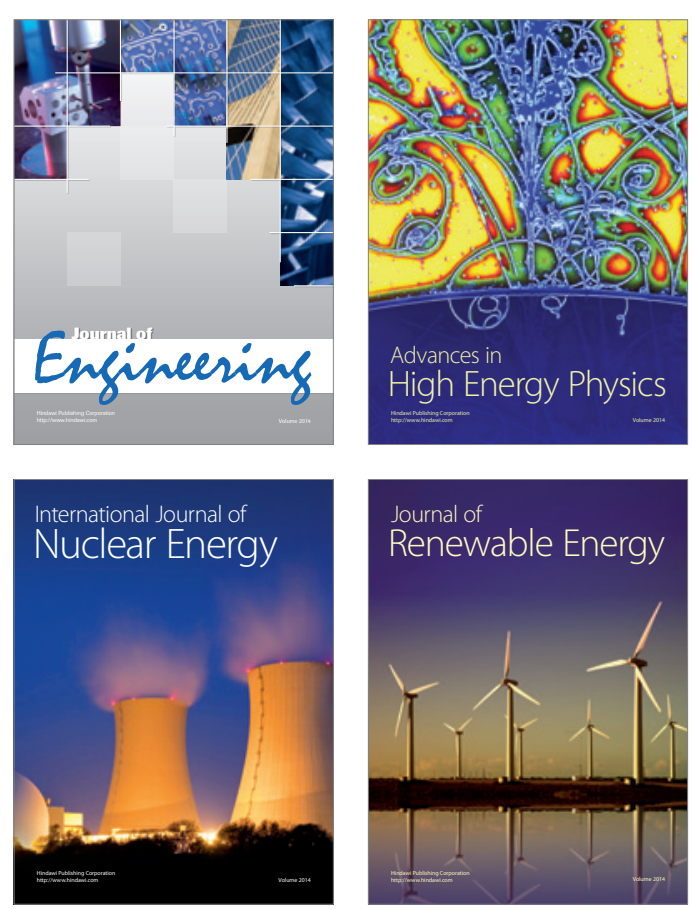

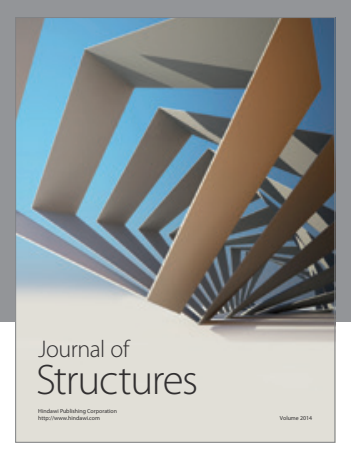

Rotating
Mechinery
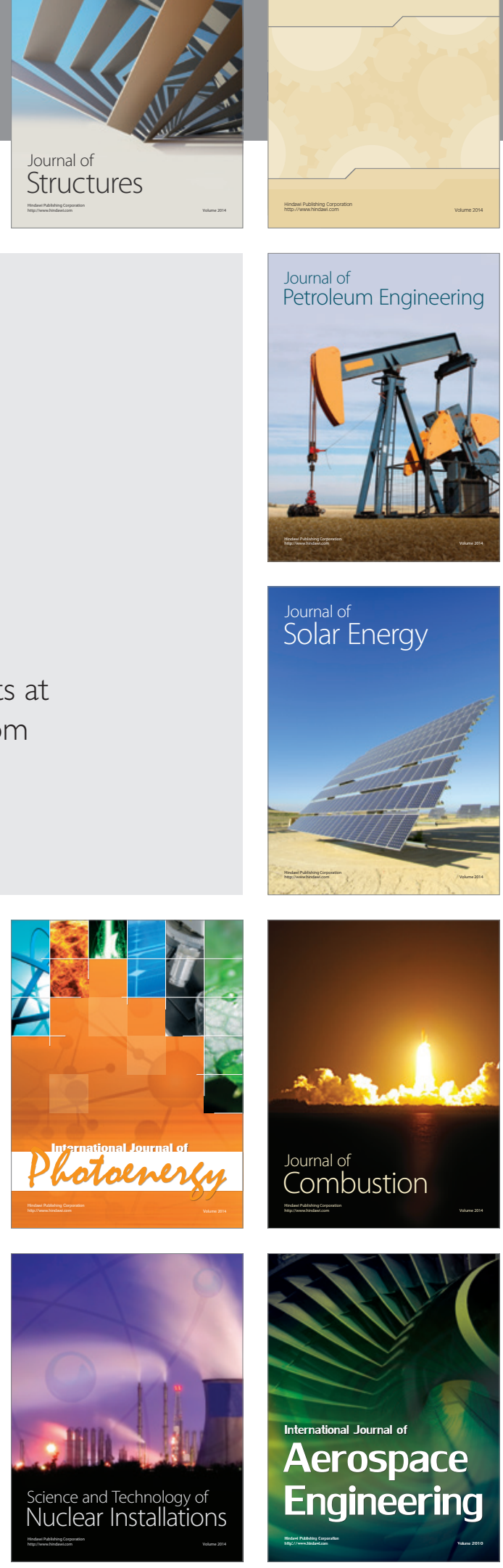